\title{
Reaction Rates and Swelling Phenomenon of Fe-C Droplets in FeO bearing Slag
}

\author{
Haiping SUN \\ School of Materials Science and Engineering, University of New South Wales, Sydney, NSW 2052 Australia. \\ E-mail: h.sun@unsw.edu.au
}

(Received on June 19, 2006; accepted on August 28, 2006)

\begin{abstract}
The reduction of $\mathrm{FeO}$ in slag by an iron droplet, decarburisation of the droplet and the droplet swelling phenomenon during slag-metal droplet reaction were analyzed by a kinetic model. Diffusions in the slag phase, diffusions throughout the droplet, interfacial reactions, equilibrium relations and homogeneous nucleation of gas bubbles within the droplet were incorporated in the model.

During an $\mathrm{Fe}-\mathrm{C}$ droplet reaction with $\mathrm{FeO}$ bearing slag, decarburisation rate increases with increasing $\mathrm{FeO}$ in slag, carbon in the droplet and the droplet size, but the rate decreases with increasing silicon in metal and ambient pressure. The decarburisation rate in unit surface area of the droplet increases with increasing the droplet size. Slow decarburisation during the initial stage of the reaction was suggested by the model, and the desiliconisation and oxygen absorption of the droplet were found to be responsible for this initial slow decarburisation. The initial slow decarburisation is pronounced when the droplet contains higher carbon and silicon, or when the reaction occurs under higher pressure and with the slag containing lower $\mathrm{FeO}$. CO bubble generation within the droplet was suggested to cause the swelling of the droplet. The occurrence of swelling is promoted when the droplet contains higher carbon and lower silicon, slag contains higher $\mathrm{FeO}$, or when the droplet is small, and the reaction occurs under lower pressure.
\end{abstract}

KEY WORDS: droplet; smelting reduction; steelmaking; decarburisation; swelling.

\section{Introduction}

Reactions between liquid iron droplets and slag occur while liquid iron droplets are ejected from the metal bath into the slag phase in the smelting reduction of iron ore and oxygen steelmaking processes. Understanding the kinetic features of the $\mathrm{FeO}$ reduction or decarburisation related to the iron droplets, and the accompanying droplet swelling phenomenon are important for describing droplets' behavior in slag. The swelling of an iron droplet in the slag will increase the reaction area and reduce the apparent density of the droplet to enhance its suspension in the slag. The droplet swelling in slag is therefore desired for high speed reduction or high speed decarburisation in the processes.

The metal droplet formation, droplet size distribution, and residence time of droplets in slag phase for steelmaking process have been investigated in many studies. ${ }^{1-6)}$ The swelling of an iron droplet under oxidizing conditions was observed by Min and Fruehan, ${ }^{7)}$ and Molloseau and Frue$\mathrm{han}^{8)}$ for an Fe-C droplet exposed to oxidizing slag. The phenomenon was also observed by Sun et al. . $^{9}$ and Gao et $a l .{ }^{10)}$ for an $\mathrm{Fe}-\mathrm{C}$ droplet exposed to oxidizing gases. Kinetic studies on the iron droplet-slag reaction have been focused to carbon, silicon and manganese transfers between slag and the droplet. ${ }^{7,8,11)}$ In the investigations of decarburisation of iron droplet by $\mathrm{FeO}$ in slags, substantial increase of the decarburisation rate was found for a swollen droplet. $^{7,8)}$ In this work, the attempts were made to interpret the reaction kinetics and the swelling phenomena.

\section{Interfacial Phenomena and Reaction Kinetics}

\subsection{CO Bubbles at the Interface}

For a gas bubble presenting at the slag-metal interface as illustrated in Fig. 1(a), the contact angle between gas bubble and metal in slag media can be estimated by balancing the interfacial forces according to Young's equation:

$$
\sigma_{\mathrm{gm}}-\sigma_{\mathrm{sm}}-\sigma_{\mathrm{gs}} \cos \theta=0 \text {. }
$$

The contact angle was calculated to be $\sim 157^{\circ}$ using the interfacial tensions between slag and metal $(\sim 1200$ $\mathrm{mN} / \mathrm{m}),{ }^{12)}$ slag and gas $(\sim 380 \mathrm{mN} / \mathrm{m}),{ }^{13)}$ and metal and gas $\left.(\sim 1550 \mathrm{mN} / \mathrm{m}) .{ }^{14}\right)$ The high contact angle indicates poor "wetting" of gas bubble with metal in slag media. From Xray fluoroscopy observations of an $\mathrm{Fe}-\mathrm{C}$ in slag, ${ }^{8)}$ the droplet appeared to be surrounded by a thin layer of slag less dense than the bulk slag during the reaction. This layer is considered to be numerous gas bubbles attached to the droplet as schematically presented in Fig. 1(b). These surface bubbles contact with the metal by limited area because of the poor "wetting".

\subsection{Elementary Steps}

The mass transfer of elements and oxides in the vicinity 


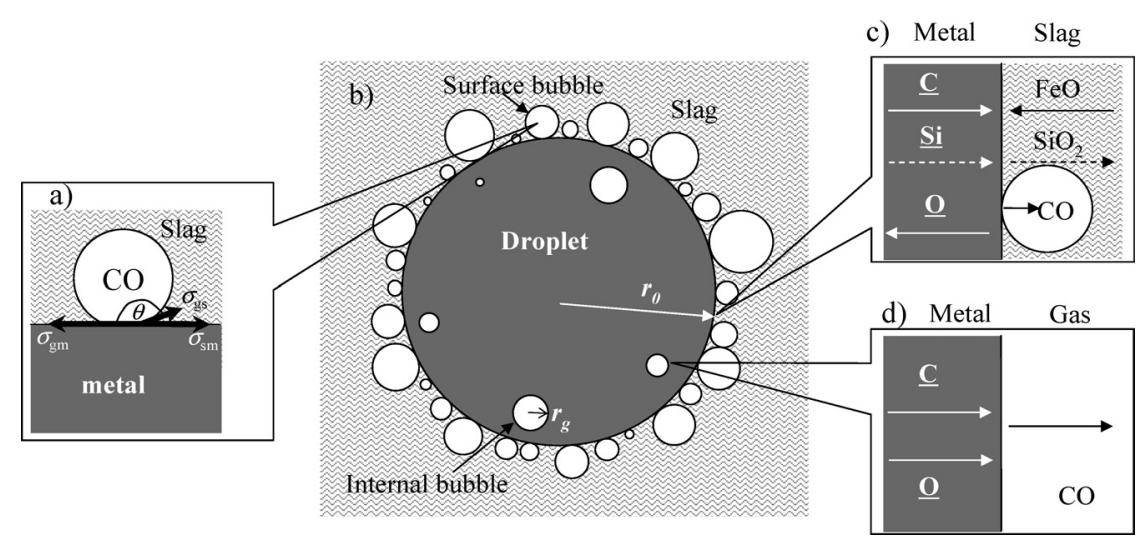

Fig. 1. Liquid $\mathrm{Fe}-\mathrm{C}$ droplet in a slag containing $\mathrm{FeO}$. (a) A gas bubble at slag-metal interface, (b) a droplet surrounded by gas bubbles, (c) mass transfers at slag-metal interface, and (d) mass transfers at gas-metal interface.

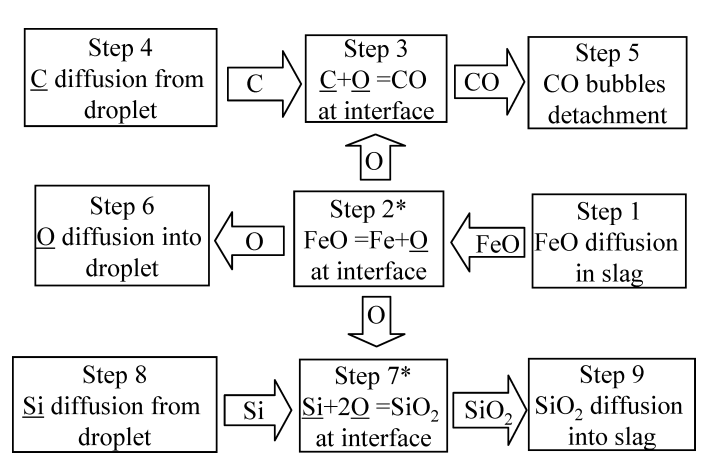

Fig. 2. Mass transfers and reactions at the slag-metal interface. Asterisks indicate the steps that are fast and the equilibria are reached at the interface.

of the interface between $\mathrm{Fe}-\mathrm{C}$ droplet and the slag containing $\mathrm{FeO}$ are shown in Fig. 1(c). If there is an internal gas bubble presenting in the droplet, the mass transfers between the internal bubble and liquid iron are shown in Fig. 1(d).

The mass transfer and interfacial reaction processes at the slag-metal interface are summarized in Fig. 2. During the reaction, the migration of $\mathrm{FeO}$ from slag bulk to the slag side of the interface occurs by $\mathrm{FeO}$ diffusion in the slag phase, or Step 1. FeO arrived at the interface undergoes the reduction reaction (2) as represented by Step 2 .

$$
\mathrm{FeO}=\mathrm{Fe}+\underline{\mathrm{O}} .
$$

The oxygen produced from the reaction (2) reacts with carbon at the interface by the reaction (3), which is represented by Step 3 .

$$
\underline{\mathrm{C}}+\underline{\mathrm{O}}=\mathrm{CO} \text {. }
$$

Reaction (3) removes oxygen at the interface supplied from Step 2 and carbon supplied from Step 4, the latter is the carbon diffusion from droplet bulk to the interface. The removal of oxygen from the interface by reaction (3) keeps the interfacial oxygen at a lower level to sustain further oxygen supply from Steps 1 and 2. Reaction (3) produces $\mathrm{CO}$ gas bubbles at the interface, and these bubbles leave the interface by Step 5 to complete decarburisation process. If oxygen supplying rate by Step 2 is higher than the oxygen removal rate by Step 3, the extra oxygen will diffuse into the droplet by Step 6. As will be discussed later, the oxygen diffusion into the droplet bulk, or oxygen absorption by the droplet, may trigger the reaction (3) to occur within the droplet as seen in Fig. 1(d). This internal reaction produces $\mathrm{CO}$ bubbles within the liquid to swell the droplet.

If silicon presents in the droplet, desiliconisation occurs at the interface by reaction (4)

$$
\underline{\mathrm{Si}}+2 \underline{\mathrm{O}}=\mathrm{SiO}_{2}
$$

This reaction, or Step 7, also removes oxygen supplied from Step 2, and silicon supplied from Step 8, the latter is the silicon diffusion from the droplet bulk to the metal side of the interface. Silica, the product of reaction (4), leaves the interface by the diffusion into slag bulk, which is represented by Step 9. If other elements such as manganese, titanium or phosphorus present in the droplet, their involvements in the kinetics can be treated in a similar manner as that for silicon.

\subsection{Limiting Steps}

These 9 steps proceed simultaneously during the reaction, those steps that process much faster than the others can be excluded from controlling steps. Diffusions of $\mathrm{FeO}$ and $\mathrm{SiO}_{2}$ in slag, i.e., Steps 1 and 9, were found to be slow in many studies ${ }^{15-21)}$ and they usually control or partly control the overall reaction rates. The reaction (2), i.e., $\mathrm{FeO}$ reduction at slag-metal interface, was found fast ${ }^{15,19,20)}$ at high temperatures. The influence of the rate of reaction (2), or Step 2, on the overall reaction rates can be excluded and it is able to assume that the equilibrium of reaction (2) is maintained at the interface. The Step 3, i.e., decarburisation reaction (3) at slag-metal interface, has been found slow $^{15,19,20,22,23)}$ and is involved in controlling the overall decarburisation rate. The $\mathrm{CO}$ bubble detachment from the interface, Step 5, is considered as a part of reaction (3) and will be dealt together with Step 3 in the subsequent model development. The mass transfers of carbon, oxygen and silicon, i.e., Steps 4, 6 and 8, were found to be slow in slag-metal reactions ${ }^{15,20-25)}$ and are involved in the kinetics of the reactions. The fast interfacial desiliconisation $^{15,17,22-25)}$ enables the equilibrium of the reaction (4) or Step 7 to be assumed at the slag-metal interface.

In summary, for an iron droplet containing carbon and silicon reacting with slag containing $\mathrm{FeO}$, Steps 2 and 7 indicated by asterisk in Fig. 2 can be excluded from rate limiting steps while other steps may affect the overall reaction rates and should be included in the kinetic model. 


\section{Kinetic Model}

\subsection{Reaction between Droplet and Slag}

\subsubsection{Rate Equations}

On the basis of the above discussions, a kinetic model was developed by including diffusions in the slag (Steps 1 and 9), diffusions in the metal (Steps 4, 6 and 8), the reaction (3) at the interface (Steps 3 and 5), and the equilibria of reactions (2) and (4) at the interface (Steps 2 and 7).

The composition of the slag bulk is uniform, and a composition profile exists only at the vicinity of the slag side of the interface where $\mathrm{FeO}$ is removed by Step 2 and $\mathrm{SiO}_{2}$ is produced by Step 7. This enables the boundary layer theory to be applied for describing the mass transfers of $\mathrm{FeO}$ and $\mathrm{SiO}_{2}$ in the slag as,

$$
\begin{gathered}
J_{\mathrm{FeO}}=\frac{A k_{\mathrm{s}} \rho_{\mathrm{s}}}{100 M_{\mathrm{FeO}}}\left\{(\mathrm{FeO})^{r_{0}}-(\mathrm{FeO})\right\} . . \\
J_{\mathrm{SuO}_{2}}=\frac{A k_{\mathrm{s}} \rho_{\mathrm{s}}}{100 M_{\mathrm{SiO}_{2}}}\left\{\left(\mathrm{SiO}_{2}\right)^{r_{0}}-\left(\mathrm{SiO}_{2}\right)\right\}
\end{gathered}
$$

where the superscript $r_{0}$ denotes the position at $r_{0}$ of the droplet and ()$^{r_{0}}$ means the concentrations at the slag side of the interface between slag and metal, and the materials fluxes are in the direction of the droplet radius.

Within the vicinity of the metal side of the interface, mass transfer rates of carbon, oxygen and silicon in the direction of the droplet radius are given by Fick's first law as,

$$
\begin{aligned}
& J_{\mathrm{C}}=\frac{A D_{\mathrm{C}} \rho_{\mathrm{m}}}{100 M_{\mathrm{C}} d r}\left\{[\mathrm{C}]^{r_{0}-d r}-[\mathrm{C}]^{r_{0}}\right\} \\
& J_{\mathrm{O}}=\frac{A D_{\mathrm{O}} \rho_{\mathrm{m}}}{100 M_{\mathrm{O}} d r}\left\{[\mathrm{O}]^{r_{0}-d r}-[\mathrm{O}]^{r_{0}}\right\} \\
& J_{\mathrm{Si}}=\frac{A D_{\mathrm{Si}} \rho_{\mathrm{m}}}{100 M_{\mathrm{Si}} d r}\left\{[\mathrm{Si}]^{r_{0}-d r}-[\mathrm{Si}]^{r_{0}}\right\}
\end{aligned}
$$

where the superscript $r_{0}$ denotes the position at $r_{0}$ of the droplet and []$^{r_{0}}$ means the concentrations at the metal side of the interface between slag and metal, and $r_{0}-d r$ denotes the position at $r_{0}-d r$ of the droplet and [ $]^{r_{0}-d r}$ means the concentrations in metal at a distance of $d r$ from the interface. As will be presented later, the concentrations at $r_{0}-d r$ is calculated from the concentration profiles in the droplet by Eqs. (27)-(29). It should be noted that the Fick's first law is applicable only when $d r \ll r_{0}$.

The driving force for the reaction (3) at the interface is the deviation from the equilibrium state, and the rate of the reaction is given by,

$$
J_{\mathrm{r}}=\frac{A k_{\mathrm{r}}}{100 M_{\mathrm{C}}}\left\{a_{\mathrm{O}}^{r_{0}} a_{\mathrm{C}}^{r_{0}}-\frac{P_{\mathrm{CO}}^{r_{0}}}{K_{\mathrm{C}}}\right\}
$$

\subsubsection{Stoichiometry}

Since there is no slag species or element that can be accumulated at the slag-metal interface during reaction, the mass transfer rates of $\mathrm{FeO}$ and $\mathrm{SiO}_{2}$ in slag, carbon, oxygen and silicon in metal or the decarburisation rate at interface can be stoichiometrically related by,

$$
\begin{array}{r}
-J_{\mathrm{r}}+J_{\mathrm{C}}=0 \ldots \ldots \ldots \ldots \\
-J_{\mathrm{FeO}}+J_{\mathrm{O}}-2 J_{\mathrm{SiO}_{2}}-J_{\mathrm{C}}=0 . \\
J_{\mathrm{Si}}-J_{\mathrm{SiO}_{2}}=0 \ldots \ldots \ldots \ldots
\end{array}
$$

\subsubsection{Equilibrium Relations}

The equilibrium constants, $K_{\mathrm{Fe}}, K_{\mathrm{C}}$ and $K_{\mathrm{Si}}$ for the reactions (2), (3) and (4), respectively, are given by,

$$
\begin{gathered}
K_{\mathrm{Fe}}=\left(\frac{a_{\mathrm{FeO}}}{a_{\mathrm{O}} a_{\mathrm{Fe}}}\right)_{\mathrm{EQ}}=\frac{a_{\mathrm{FeO}}^{r_{0}}}{a_{\mathrm{O}}^{r_{0}} a_{\mathrm{Fe}}^{r_{0}}} . . . \\
K_{\mathrm{C}}=\left(\frac{P_{\mathrm{CO}}}{a_{\mathrm{C}} a_{\mathrm{O}}}\right)_{\mathrm{EQ}} \ldots \ldots \ldots . . \\
K_{\mathrm{Si}}=\left(\frac{a_{\mathrm{SiO}_{2}}}{a_{\mathrm{O}}^{2} a_{\mathrm{Si}}}\right)_{\mathrm{EQ}}=\frac{a_{\mathrm{SiO}_{2}}^{r_{0}}}{\left(a_{\mathrm{O}}^{r_{0}}\right)^{2} a_{\mathrm{Si}}^{r_{0}}} . . .
\end{gathered}
$$

Note that the reactions (2) and (4) reach equilibria at the interface as discussed in Sec. 2.3., and their equilibrium constants may be represented by the interfacial values as seen in relations (14) and (16).

\subsubsection{Activities}

In slag, the activities of $\mathrm{FeO}$ and $\mathrm{SiO}_{2}$ at the interface are determined from Raoult's law with the activity coefficients,

$$
\begin{aligned}
& a_{\mathrm{FeO}}^{r_{0}}=\gamma_{\mathrm{FeO}} X_{\mathrm{FeO}}^{r_{0}} \\
& a_{\mathrm{SiO}_{2}}^{r_{0}}=\gamma_{\mathrm{SiO}_{2}} X_{\mathrm{SiO}_{2}}^{r_{0}}
\end{aligned}
$$

Where the molar fractions of $\mathrm{FeO}$ and $\mathrm{SiO}_{2}$ at the slag side of the interface are calculated for $\mathrm{CaO}-\mathrm{SiO}_{2}-\mathrm{MgO}-\mathrm{FeO}$ slag of a composition in weight percent by,

$$
\begin{gathered}
X_{\mathrm{FeO}}^{r_{0}}=\frac{(\mathrm{FeO})^{r_{0}}}{M_{\mathrm{FeO}} \Sigma} \\
X_{\mathrm{SiO}_{2}}^{r_{0}}=\frac{\left(\mathrm{SiO}_{2}\right)^{r_{0}}}{M_{\mathrm{SiO}_{2}} \Sigma}
\end{gathered}
$$

Where

$$
\Sigma=\frac{(\mathrm{FeO})^{r_{0}}}{M_{\mathrm{FeO}}}+\frac{\left(\mathrm{SiO}_{2}\right)^{r_{0}}}{M_{\mathrm{SiO}_{2}}}+\frac{(\mathrm{CaO})^{r_{0}}}{M_{\mathrm{CaO}}}+\frac{(\mathrm{MgO})^{r_{0}}}{M_{\mathrm{MgO}}}
$$

In metal, the activities of carbon, oxygen or silicon at the metal side of the interface are determined by activity coefficients and composition at the metal side of the interface according to Henrian law,

$$
\begin{aligned}
& a_{\mathrm{C}}^{r_{0}}=f_{\mathrm{C}}^{r_{0}}[\mathrm{C}]^{r_{0}} \\
& a_{\mathrm{O}}^{r_{0}}=f_{\mathrm{O}}^{r_{0}}[\mathrm{O}]^{r_{0}} \\
& a_{\mathrm{Si}}^{r_{0}}=f_{\mathrm{Si}}^{r_{0}}[\mathrm{Si}]^{r_{0}}
\end{aligned}
$$

The activity coefficients are obtained by interaction parameters and metal composition at the interface,

$$
\begin{aligned}
\log f_{\mathrm{C}}^{r_{0}} & =e_{\mathrm{C}}^{\mathrm{C}}[\mathrm{C}]^{r_{0}}+e_{\mathrm{C}}^{\mathrm{O}}[\mathrm{O}]^{r_{0}}+e_{\mathrm{C}}^{\mathrm{S}}[\mathrm{S}]^{r_{0}}+e_{\mathrm{C}}^{\mathrm{Si}}[\mathrm{Si}]^{r_{0}} . . \\
\log f_{\mathrm{O}}^{r_{0}} & =e_{\mathrm{O}}^{\mathrm{C}}[\mathrm{C}]^{r_{0}}+e_{\mathrm{O}}^{\mathrm{O}}[\mathrm{O}]^{r_{0}}+e_{\mathrm{O}}^{\mathrm{S}}[\mathrm{S}]^{r_{0}}+e_{\mathrm{O}}^{\mathrm{Si}}[\mathrm{Si}]^{r_{0}} \ldots \\
\log f_{\mathrm{Si}}^{r_{0}} & =e_{\mathrm{Si}}^{\mathrm{C}}[\mathrm{C}]^{r_{0}}+e_{\mathrm{Si}}^{\mathrm{O}}[\mathrm{O}]^{r_{0}}+e_{\mathrm{Si}}^{\mathrm{S}}[\mathrm{S}]^{r_{0}}+e_{\mathrm{Si}}^{\mathrm{Si}}[\mathrm{Si}]^{r_{0}} .
\end{aligned}
$$




\subsubsection{Determination of Interfacial Quantities}

$\mathrm{CO}$ pressure at slag-metal interface is assumed to be equal to the ambient pressure. The activity of iron at surface is assumed to be unit for an iron based droplet. Since $\mathrm{CaO}, \mathrm{MgO}$ and sulphur are not directly involved in the reaction when slag contains relatively higher $\mathrm{FeO}$, their concentrations at the interface are approximately equal to their bulk counterparts. We therefore have $P_{\mathrm{CO}}^{r_{0}}=P^{\circ}, a_{\mathrm{Fe}}^{r_{0}}=1$, $(\mathrm{CaO})^{r_{0}}=(\mathrm{CaO}),(\mathrm{MgO})^{r_{0}}=(\mathrm{MgO})$ and $[\mathrm{S}]^{r_{0}}=[\mathrm{S}]$.

There are 15 interfacial values are needed to be determined for the reaction rate calculation. These values are, $a_{\mathrm{FeO}}^{r_{0}}, a_{\mathrm{SiO}_{2}}^{r_{0}}, X_{\mathrm{FeO}}^{r_{0}}, X_{\mathrm{SiO}_{2}}^{r_{0}},(\mathrm{FeO})^{r_{0}},\left(\mathrm{SiO}_{2}\right)^{r_{0}}, a_{\mathrm{C}}^{r_{0}}, a_{\mathrm{O}}^{r_{0}}, a_{\mathrm{Si}}^{r_{0}},[\mathrm{C}]^{r_{0}}$, $[\mathrm{O}]^{r_{0}},[\mathrm{Si}]^{r_{0}}, f_{\mathrm{C}}^{r_{0}}, f_{\mathrm{O}}^{r_{0}}$, and $f_{\mathrm{Si}}^{r_{0}}$. These unknown values can be solved by 15 relations. These relations are three stoichiometrical relations (11)-(13), two equilibrium relations (14) and (16), and ten activity relations (17)-(26). With the solution of these interfacial values, the rate of each element transport across slag-metal interface can be determined from Eqs. (5)-(10).

\subsubsection{Mass Transfers in the Droplet}

The concentration profiles of carbon, oxygen and silicon in the droplet are obtained by applying Fick's second diffusion law to a sphere as,

$$
\begin{aligned}
& \frac{\partial[\mathrm{C}]}{\partial t}=D_{\mathrm{C}}\left\{\frac{2}{r} \cdot \frac{\partial[\mathrm{C}]}{\partial r}+\frac{\partial^{2}[\mathrm{C}]}{\partial r^{2}}\right\} \ldots \ldots \ldots \ldots . . . \\
& \frac{\partial[\mathrm{O}]}{\partial t}=D_{\mathrm{O}}\left\{\frac{2}{r} \cdot \frac{\partial[\mathrm{O}]}{\partial r}+\frac{\partial^{2}[\mathrm{O}]}{\partial r^{2}}\right\} \ldots \ldots \ldots \ldots . .(28 \\
& \frac{\partial[\mathrm{Si}]}{\partial t}=D_{\mathrm{Si}}\left\{\frac{2}{r} \cdot \frac{\partial[\mathrm{Si}]}{\partial r}+\frac{\partial^{2}[\mathrm{Si}]}{\partial r^{2}}\right\} \ldots \ldots \ldots \ldots . . .
\end{aligned}
$$

Using the concentrations of carbon, oxygen and silicon obtained at the interface in the previous section, $[\mathrm{C}]^{r_{0}},[\mathrm{O}]^{r_{0}}$ and $[\mathrm{Si}]^{r_{0}}$, as the boundary conditions, and assuming that composition of the droplet is uniform before the reaction, the concentrations of carbon, oxygen and silicon in the droplet as a function of the distance from the droplet surface and reaction time can be determined by Eqs. (27)-(29). The concentrations at $r_{0}-d r$ obtained from these calculations were used in Eqs. (7)-(9) for the determination of diffusion rates in Steps 4, 6 and 8.

\subsubsection{Thermodynamic and Kinetic Parameters}

To determine the reaction rates, relevant thermodynamic and kinetic parameters must be provided. The equilibrium constants and interaction parameters ${ }^{26)}$ were used to calculate $K_{\mathrm{Fe}}, K_{\mathrm{C}}$ and $K_{\mathrm{Si}}$, and the activity coefficients for metal components. The activities of $\mathrm{FeO}^{27)}$ and $\mathrm{SiO}_{2}{ }^{28)}$ in $\mathrm{CaO}-\mathrm{SiO}_{2}-\mathrm{MgO}-\mathrm{FeO}$ slag were used to estimate the activity coefficients in the slag. The mass transfer coefficient in slag phase ${ }^{29)}$ and reaction rate constant for reaction $(3)^{15)}$ were selected for $k_{\mathrm{s}}$ and $k_{\mathrm{r}}$, respectively. Diffusivities of carbon, ${ }^{30)}$ oxygen, ${ }^{31)}$ and silicon ${ }^{32)}$ in molten iron as a function of the temperature were used for $D_{\mathrm{C}}, D_{\mathrm{O}}$ and $D_{\mathrm{Si}}$, respectively.

\subsection{Stable CO Bubble in Metal}

Once carbon and oxygen in the droplet become higher than the equilibrium as presented in relation (15), reaction (3) may occur in the droplet. When an instantaneous $\mathrm{CO}$ cluster is larger than a critical bubble size, the cluster will spontaneously grow into a bubble within the droplet. The critical bubble radius, $r_{\mathrm{g}}$, is estimated from a stable gas bubble in a liquid. For a stable $\mathrm{CO}$ bubble in liquid iron, the sum of the pressure due to the surface tension and the ambient pressure must be balanced by $\mathrm{CO}$ pressure through,

$$
P_{\mathrm{CO}}=2 \sigma_{\mathrm{gm}} / r_{\mathrm{g}}+P^{\circ}
$$

where $P_{\mathrm{CO}}$ is the $\mathrm{CO}$ pressure in equilibrium with carbon and oxygen in the liquid iron.

Under a given ambient pressure, $P^{\circ}$, the critical bubble radius is determined by $P_{\mathrm{CO}}$ and $\sigma_{\mathrm{gm}} \cdot P_{\mathrm{CO}}$ and $\sigma_{\mathrm{gm}}$ are in turn determined by the metal composition and temperature according to Eq. (15) and the surface tensions for $\mathrm{Fe}-\mathrm{O}-\mathrm{S}$ melts, ${ }^{14)}$ respectively.

$r_{\mathrm{g}}$ calculated from Eq. (30) is the minimum stable $\mathrm{CO}$ bubble size in liquid. The nucleation of an internal $\mathrm{CO}$ bubble or the occurrence of the internal reaction is likely to occur when $r_{\mathrm{g}}$ is small because the higher possibility of $\mathrm{CO}$ clusters having a size over a smaller $r_{\mathrm{g}}$. Any factors that reduce $r_{\mathrm{g}}$ would increase the possibility of $\mathrm{CO}$ nucleation, and therefore the swelling of the droplet.

If there are inclusions in the droplet, and these inclusions have a good wetting with gas than with slag, the inclusions may provide sites for heterogeneous nucleation of $\mathrm{CO}$ bubble. The heterogeneous nucleation is much easier than that of homogeneous since for the same critical bubble radius, critical bubble volume for heterogeneous nucleation is smaller than that of homogeneous nucleation. Hence, the present of such inclusions will increase the possibility of $\mathrm{CO}$ nucleation, and therefore, promote the swelling of the droplet.

\section{Results and Discussions}

\subsection{Reaction Rates}

The model calculation was carried out for an 1 gram iron droplet containing 2.91 mass $\%$ carbon, 0.002 mass $\%$ oxygen and 0.011 mass\% sulphur reacting with $\mathrm{CaO}-\mathrm{MgO}-$ $\mathrm{SiO}_{2}-\mathrm{FeO}$ slag of $\mathrm{CaO} / \mathrm{SiO}_{2}$ ratio of $1.2,12$ mass $\% \mathrm{MgO}$ and $3-20$ mass $\% \mathrm{FeO}$ at $1713 \mathrm{~K}$. Except the oxygen content in the droplet was estimated from the equilibrium of reaction (3), these conditions are the same conditions as those used in the experimental observations. ${ }^{8)}$ The calculated decarburisation rates during initial $60 \mathrm{~s}$ are compared with observed rates in Table 1. The calculations agree with the observed ones when $\mathrm{FeO}$ is less than 5 mass $\%$. Beyond 10 mass $\% \mathrm{FeO}$, the calculations are much slower than the observed. This is because the droplet swelled for slag containing more than 10 mass $\% \mathrm{FeO}^{7,8)}$ and the reaction model did not include the increased surface area, the internal decarburisation, and enhanced mass transfer rate in a swollen droplet.

The variations of $\mathrm{CO}$ generation, $\mathrm{FeO}$ reduction and oxygen absorption rates during the reaction with slag of 5 mass\% FeO are shown in Fig. 3(a). The reaction rates de- 
Table 1. CO generation rates during $60 \mathrm{~s}$.

\begin{tabular}{cccccc}
\hline FeO, mass\% & 3 & 5 & 10 & 15 & 20 \\
\hline Droplet swelling $^{8)}$ & no & no & yes & yes & yes \\
$J_{\mathrm{CO}} \times 10^{6}$, mol $/ \mathrm{s}$, observed $^{8)}$ & $3.3 \sim 3.3$ & $3.0 \sim 3.0$ & $30 \sim 1$ & $180 \sim 1$ & $200 \sim 1.1$ \\
$J_{\mathrm{CO}} \times 10^{6}, \mathrm{~mol} / \mathrm{s}$, calculated* & $1.73 \sim 1.70$ & $3.01 \sim 2.89$ & $6.13 \sim 5.55$ & $9.17 \sim 7.71$ & $12.2 \sim 9.40$ \\
\hline
\end{tabular}

*calculated $J_{\mathrm{CO}}$ during stagnant decarburisation period were not included.
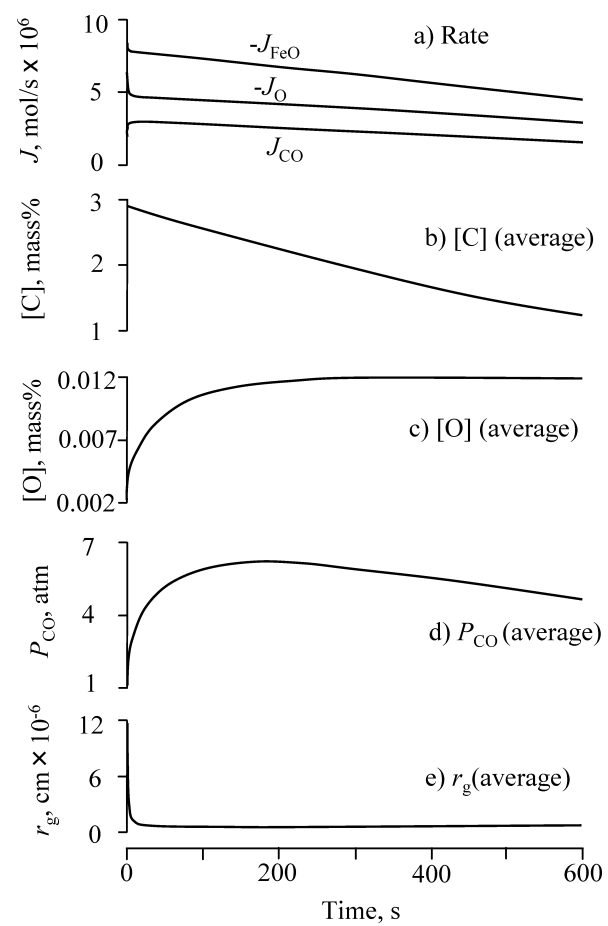

Fig. 3. Rates of $\mathrm{CO}$ generation, oxygen absorption and $\mathrm{FeO}$ reduction (a), average concentrations of carbon (b) and oxygen (c), average $\mathrm{CO}$ pressure (d), and average critical bubble radius (e) during the reaction of a $1 \mathrm{~g}$ droplet (2.91 mass \% carbon) reacting with slag ( 5 mass \% FeO) at $1713 \mathrm{~K}$.

creases with reaction time as reactions approaching the equilibria. Surprisingly, less than one half of oxygen brought by the reduction of $\mathrm{FeO}$ to the interface is removed by decarburisation, and the rest is absorbed by the droplet. Carbon content, silicon content, $\mathrm{CO}$ pressure, and critical bubble size are largely distributed quantities in the droplet. Their average values may be obtained from the integration across the droplet radius. For example, the average content of carbon in the droplet is obtained by,

$$
[\mathrm{C}]_{\mathrm{av}}=\int_{0}^{r_{0}} \frac{3 r^{2}}{r_{0}^{3}}[\mathrm{C}] d r
$$

As shown in Figs. 3(b) and 3(c), average carbon decreases and average oxygen increases with increasing reaction time; the average $\mathrm{CO}$ pressure increases and average critical bubble radius decreases. The droplet may not swell immediate after contacting the slag; a time period may be required for building up an over-saturation level for the $\mathrm{CO}$ bubble nucleation within the droplet. This corresponds qualitatively to the observations ${ }^{8)}$ that there were a time period required for the occurrence of droplet emulsion, and the period length depends on the conditions.

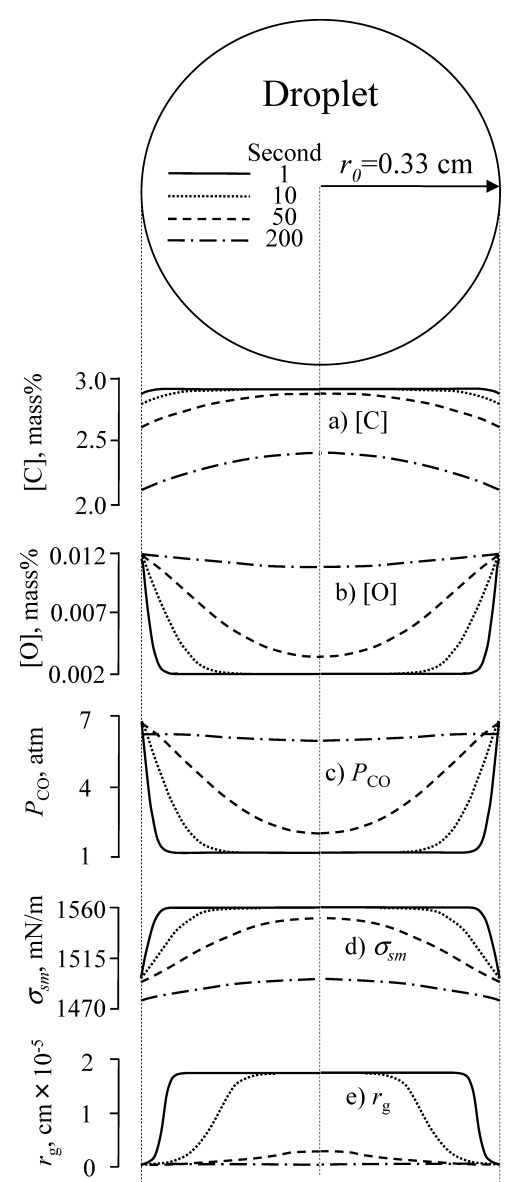

Fig. 4. Profiles of carbon concentration (a), oxygen concentration (b), CO pressure (c), surface tension (d) and critical bubble radius (e) at 1, 10, 50 and $200 \mathrm{~s}$ into reaction between a $1 \mathrm{~g}$ droplet $(2.91$ mass $\%$ carbon) and slag ( 5 mass\% FeO) at $1713 \mathrm{~K}$.

\subsection{Profiles in the Droplet}

Figures 4(a)-4(e) show the concentrations of carbon and oxygen, $\mathrm{CO}$ pressure in equilibrium with the local metal composition, surface tension and critical bubble size in a $\mathrm{Fe}-\mathrm{C}$ droplet as functions of radius in the droplet and reaction times $(1,10,50$ and $200 \mathrm{~s})$ with the slag containing 5 mass $\% \mathrm{FeO}$ at $1713 \mathrm{~K}$. After $1 \mathrm{~s}$ of the reaction, carbon decreases in the vicinity of the droplet surface while remains unchanged at the droplet center. As shown by the curves for 10,50 and $200 \mathrm{~s}$ of the reaction time, carbon concentration in the droplet decreases. Oxygen at the interface is kept high and diffuses into the droplet to create a profile in an opposite direction to that of carbon. The $\mathrm{CO}$ pressure in the droplet increases with the reaction time. When CO pressure becomes greater than the ambient pressure ( $1 \mathrm{~atm})$, the metal is said to be supersaturated, and the internal reaction (3) becomes possible. The surface tension decreases with time due to the increased oxygen. Critical bubble size near the surface is lower than those at the cen- 
Table 2. Average decarburisation rate during $60 \mathrm{~s}$ of reaction $\left(J_{\mathrm{C}}\right)$, reaction times required for $1 \%$ decarburization $\left(t_{1 \%}\right)$ and reaching max decarburisation rate $\left(t_{\max }\right)$, and average critical bubble size $\left(r_{\mathrm{g}, \mathrm{av}}\right)$ in the droplet after $10 \mathrm{~s}$ reaction in slag.

\begin{tabular}{ccccccc}
\hline Rate, time and $r_{\text {g.av }}$ & Reference & $\begin{array}{c}\mathrm{FeO}=3 \\
\text { mass\% }\end{array}$ & $\begin{array}{c}{[\mathrm{C}]=4.5} \\
\text { mass } \%\end{array}$ & $\begin{array}{c}{[\mathrm{Si}]=0.5} \\
\text { mass } \%\end{array}$ & $\begin{array}{c}W_{\mathrm{d}}=0.5 \\
\mathrm{~g}\end{array}$ & $\begin{array}{c}P^{\circ}=5 \\
\text { atm }\end{array}$ \\
\hline$J_{\mathrm{C}}, \mathrm{mol} / \mathrm{s} \times 10^{6}$ & 2.95 & 1.72 & 3.42 & 2.12 & 1.73 & 2.11 \\
$t_{1 \%}, \mathrm{~s}$ & 8 & 14 & 11 & 18 & 7 & 10 \\
$t_{\max }, \mathrm{s}$ & 5 & 7 & 17 & 105 & 5 & 6 \\
$r_{\mathrm{g}, \mathrm{av}}, \mathrm{cm} \times 10^{6}$ & 1.31 & 2.38 & 1.16 & 1.94 & 1.08 & $\infty$ \\
\hline
\end{tabular}

* Reference case: 1 gram droplet containing 2.9 mass $\%$ carbon, 0.002 mass $\%$ oxygen and 0.01 mass $\%$ sulfur, slag of $\mathrm{CaO} / \mathrm{SiO}_{2}=1.2$ and containing 12 mass $\% \mathrm{MgO}$ and 5 mass $\% \mathrm{FeO}$ at $1713 \mathrm{~K}$.

ter, and decreases with time. This indicates that $\mathrm{CO}$ bubble nucleation is easier at the regions close to the droplet surface or after longer reaction time. This corresponds well with X-ray observations ${ }^{7)}$ of a swollen droplet in slag where the droplet center was found denser than the circumferential region of the droplet.

\subsection{Influence of Variables on the Reaction Rates and the Droplet Swelling}

Several reaction cases were modeled within $60 \mathrm{~s}$ reaction using conditions given in Table 2. The reference case is an 1 gram droplet containing 2.9 mass $\%$ carbon, 0.002 mass $\%$ oxygen and $0.01 \mathrm{mass} \%$ sulphur reacting with a slag of 5 mass $\% \mathrm{FeO}$ at $1713 \mathrm{~K}$. The influence of a variable was examined by varying the variable as shown in Table 2 while keeping other variables same as the reference case. The influence of $\mathrm{FeO}$ in slag, carbon and silicon contents in the droplet, droplet size, and ambient pressure were investigated. The average decarburisation rate during $60 \mathrm{~s}$ of reaction $\left(J_{\mathrm{C}}\right)$, reaction time required for removing $1 \%$ of total carbon in the droplet $\left(t_{1 \%}\right)$, reaction time required for reaching max decarburisation rate $\left(t_{\max }\right)$, and average critical bubble size $\left(r_{\mathrm{g}, \mathrm{av}}\right)$ after $10 \mathrm{~s}$ reaction were investigated and will be discussed in the following sections.

\subsubsection{Decarburisation Rate}

The decarburisation rate, $J_{\mathrm{C}}$, obtained with varying variables is compared with the reference case in Table 2. Decarburisation rate increases with increasing $\mathrm{FeO}$ in slag, carbon in the droplet and the size of droplet, but the rate decreases with increasing silicon in the droplet and ambient pressure. It is noted that the decarburisation rate in unit surface area of the droplet also increases with increasing the droplet size. On the qualitative base, these tendencies are in agreement with observations on the influences of $\mathrm{FeO}$ in slag, carbon in the droplet and droplet size, ${ }^{7,8)}$ silicon in metal $^{15)}$ and pressure ${ }^{33)}$ on the decarburisation rate.

\subsubsection{Retardation Period}

A slow decarburisation rate at initial several seconds of slag-metal reaction was observed. ${ }^{7,8,34)}$ This period is referred as the retardation periods. Figure 5 shows the reaction or mass transfer rates versus logarithm of reaction time for reference case (Ref), and cases of high carbon (4.5 mass $\%)$, high silicon $(0.5 \mathrm{mass} \%)$ and low $\mathrm{FeO}$ ( 3 mass $\%$ ). The decarburisation starts slowly and progressively increases in the first several seconds for all cases as shown in Fig. 5(a). This is because the Steps 6 or 7 removes oxygen from the interface and less oxygen can be provided
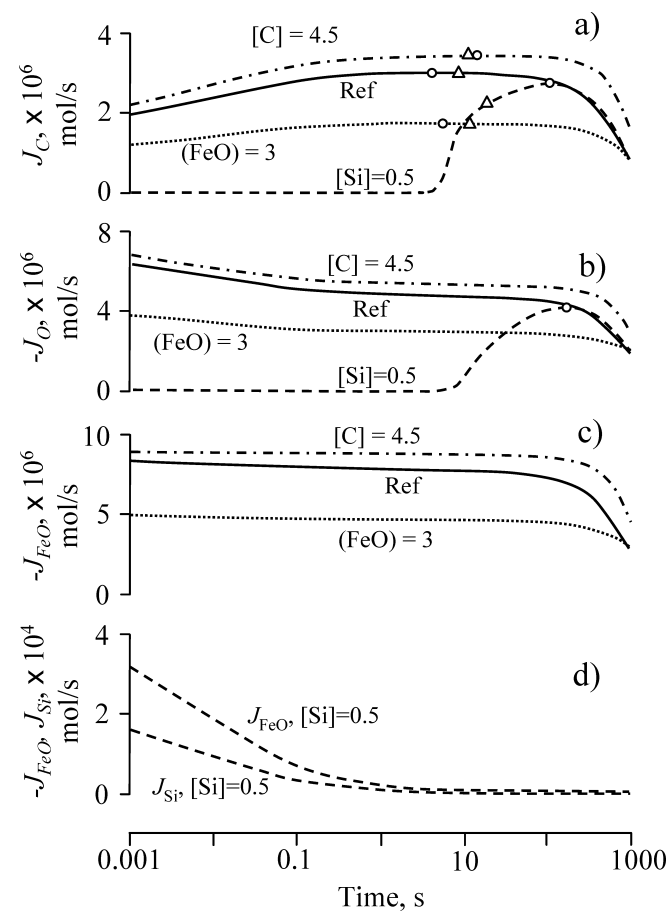

Fig. 5. Changes of $\mathrm{CO}$ generation (a), oxygen absorption (b), $\mathrm{FeO}$ reduction or diffusion (c, d), and silicon transfer (d) rates with time. The conditions for reference case (Ref) are a $1 \mathrm{~g}$ droplet $(2.91 \mathrm{mass} \%$ carbon, 0 mass $\%$ silicon) reacting with slag $(5 \mathrm{mass} \% \mathrm{FeO})$ at $1713 \mathrm{~K}$. Triangles and circles indicate reaction times required for $1 \%$ decarburization $\left(t_{1 \%}\right)$ and for reaching max decarburisation rate $\left(t_{\max }\right)$ or the maximum rates, respectively.

for decarburisation in this period. Since initial oxygen is lower in the metal, the oxygen diffusion (Step 6) is initially faster as shown in Fig. 5(b), which keeps interfacial oxygen at a low level to retard decarburisation. When silicon is present in the droplet, the desiliconisation keeps oxygen even lower. The decarburisation will not increase markedly until the desiliconisation becomes relaxed. As seen from curves of $[\mathrm{Si}]=0.5 \mathrm{mass} \%$ in Figs. $5(\mathrm{a})$ and $5(\mathrm{~b})$, both decarburisation and oxygen absorption rates increase markedly only after vigorous desiliconisation as shown in Fig. 5(d). A retardation period of decarburisation may be quantified by using the reaction time required for removing $1 \%$ of total carbon in the droplet. The retardation periods, $t_{1 \%}$, for all cases are listed in Table 2 as well as shown by triangle marks in Fig. 5(a). Comparing with the reference case (Ref), the conditions that favor a longer retardation period of decarburisation was found to be higher carbon and higher silicon in the droplet, higher pressure, and lower $\mathrm{FeO}$ in the slag. 
As reaction time further increases, the depletion of carbon in the droplet will bring the decarburisation rate down until the equilibrium of the reaction is achieved. There exists a maximum decarburisation rate during reaction. The maximum decarburisation rates are marked by the circles in Fig. 5(a). When silicon presents in the droplet, a maximum oxygen absorption rate as marked by a circle in Fig. 5(b) occurs for the similar reason. The time periods required for decarburisation reaching the maximum rate are also listed in Table 2. When the droplet contains higher carbon and silicon, slag contains lower $\mathrm{FeO}$, longer time period is required for the decarburisation to reach the maximum rate.

\subsubsection{FeO Reduction Rate}

The reduction rate of $\mathrm{FeO}$, which is equal to $\mathrm{FeO}$ diffusion rate, as presented in Figs. 5(c) and 5(d), increases with carbon and silicon contents in the droplet because increased oxygen removal rate by decarburisation and desiliconisation. The reduction rate of $\mathrm{FeO}$ increases with increasing $\mathrm{FeO}$ in slag because the driving force for the $\mathrm{FeO}$ diffusion is increased.

\subsubsection{Influence of Variables on Droplet Swelling}

Average critical bubble size $\left(r_{\mathrm{g}, \mathrm{av}}\right)$ after $10 \mathrm{~s}$ reaction are given in Table 2. By comparing $r_{\mathrm{g}, \text { av }}$ of the reference case with those of other cases, the conditions that promote swelling of the droplet can be identified because of high

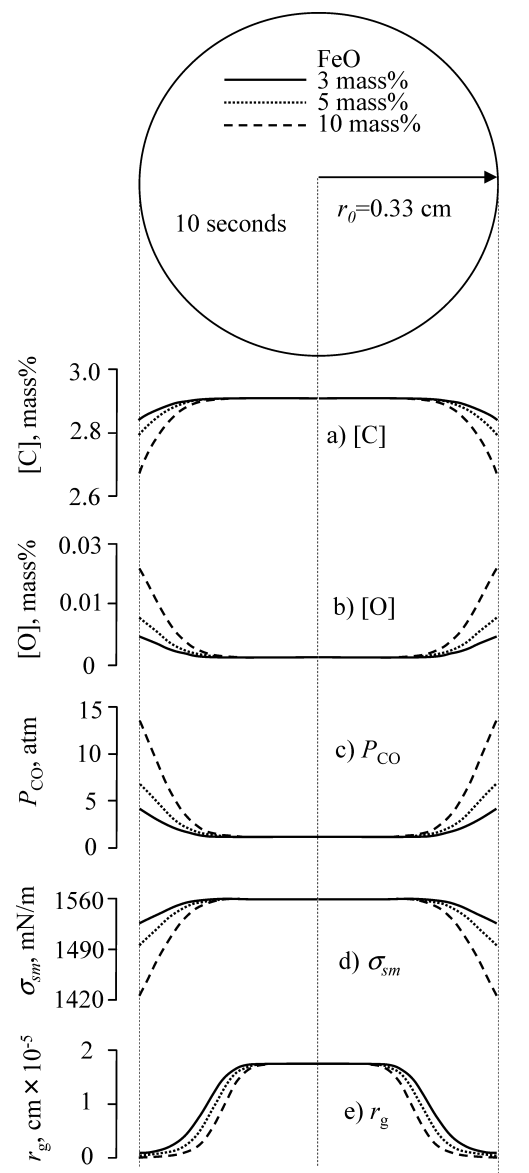

Fig. 6. Profiles of carbon concentration (a), oxygen concentration (b), CO pressure (c), surface tension (d) and critical bubble radius (e) at $10 \mathrm{~s}$ into reaction between a $1 \mathrm{~g}$ droplet (2.91 mass\% carbon) and slag $(3,5$ or 10 mass $\%$ $\mathrm{FeO})$ at $1713 \mathrm{~K}$. probability of the bubble nucleation in the liquid if $r_{\mathrm{g}, \mathrm{av}}$ is small. The swelling of the droplet would be promoted when the droplet contains higher carbon or lower silicon, slag contains higher $\mathrm{FeO}$, the droplet is smaller, or ambient pressure is lower.

Figure 6 shows the effect of $\mathrm{FeO}$ on the profiles in the droplet after $10 \mathrm{~s}$ into reaction. Carbon decreases and oxygen increases with increasing $\mathrm{FeO}$ in slag. The increase of $\mathrm{CO}$ pressure with increasing $\mathrm{FeO}$ is the net result of the decrease of carbon, which decreases $P_{\mathrm{CO}}$, and the increase of oxygen, which increases $P_{\mathrm{CO}}$. The surface tension is decreased by the increased oxygen. The critical bubble radius decreases as $\mathrm{FeO}$ increases which mean the nucleation of gas bubbles in the droplet becomes easier. This prediction corresponds well with the observation ${ }^{8)}$ that the swelling of the droplet is favored for high $\mathrm{FeO}$ in the slag.

The effect of initial carbon was examined by comparing profiles for the droplet of 2.9 mass $\%$ carbon (solid lines) with those of 4.5 mass $\%$ carbon (dash-dot lines) at $10 \mathrm{~s}$ of the reaction in Fig. 7. There is no large difference for oxygen between two cases. CO pressure increases and surface tension decreases with increasing initial carbon in the droplet. The critical bubble radius is smaller for high carbon droplet, and therefore, the bubble nucleation or the

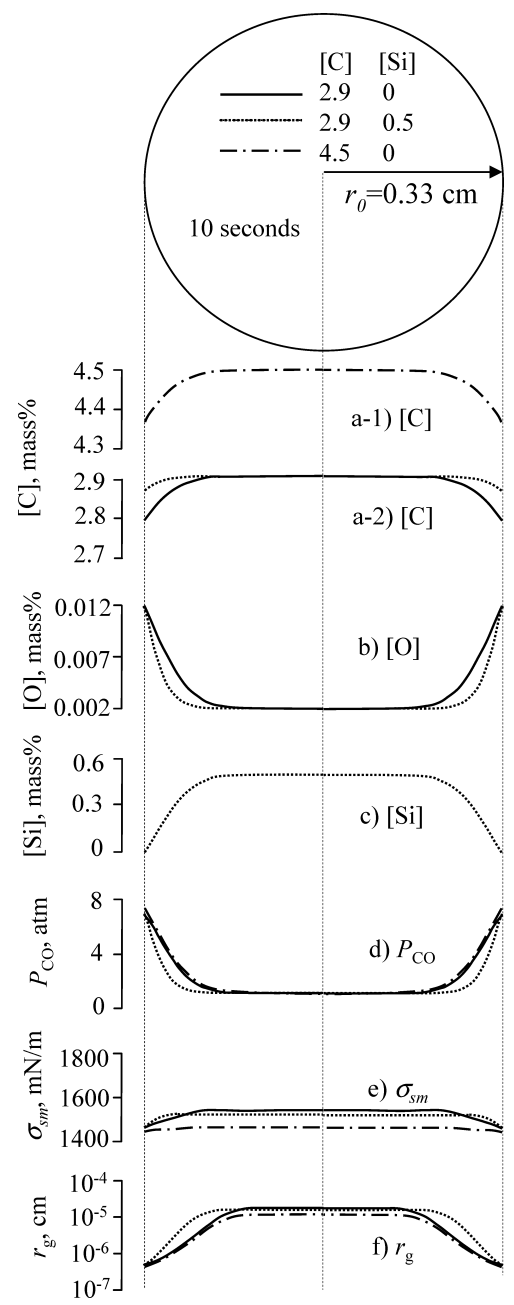

Fig. 7. Profiles of carbon (a), oxygen (b), silicon (c) concentrations, CO pressure (d), surface tension (e) and critical bubble radius (f) at $10 \mathrm{~s}$ into reaction between a $1 \mathrm{~g}$ droplet (2.91 or 4.5 mass $\%$ carbon, 0 or 0.5 mass $\%$ silicon) and slag ( 5 mass $\% \mathrm{FeO})$ at $1713 \mathrm{~K}$. 


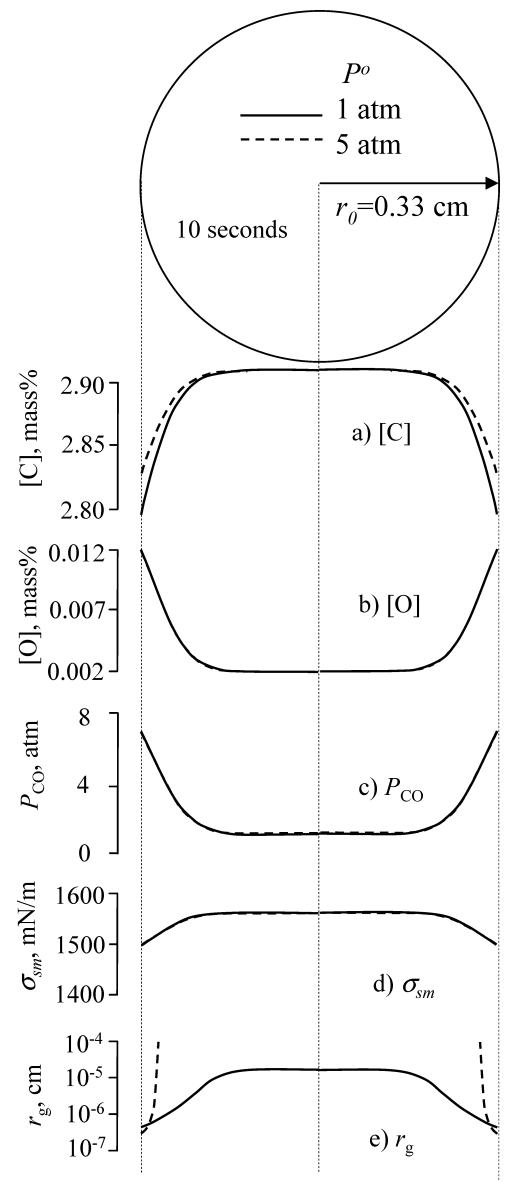

Fig. 8. Profiles of carbon concentration (a), oxygen concentration (b), CO pressure (c), surface tension (d) and critical bubble radius (e) at $10 \mathrm{~s}$ into reaction between a $1 \mathrm{~g}$ droplet (2.91 mass\% carbon) and slag (5 mass\% $\mathrm{FeO})$ under 1 or $5 \mathrm{~atm}$ at $1713 \mathrm{~K}$.

droplet swelling would be easier for higher carbon metal.

The droplet contains 0.5 mass $\%$ silicon (dotted lines) was compared with that without silicon (solid lines) in Fig. 7. Due to the suppressions of both decarburisation and oxygen absorption by desiliconisation, oxygen and $P_{\mathrm{CO}}$ are lower for the droplet containing silicon. There is no significant change in the surface tension by adding silicon to the metal. The larger critical bubble radius for the silicon bearing droplet indicates that silicon will suppress droplet swelling.

The profiles in the droplet obtained for $5 \mathrm{~atm}$ (dashed lines) were compared with those at $1 \mathrm{~atm}$ (solid lines) in Fig. 8. Carbon is higher under $5 \mathrm{~atm}$ than that under $1 \mathrm{~atm}$ because the decarburisation is suppressed by the increased pressure. The changes in profiles of oxygen, $P_{\mathrm{CO}}$ and surface tension are insignificant. Critical bubble radius increases with increasing ambient pressure, and becomes infinity when ambient pressure is greater than $P_{\mathrm{CO}}$. Therefore, the nucleation of $\mathrm{CO}$ bubble within the liquid would be difficult under higher pressure.

Profiles for $0.5 \mathrm{~g}$ droplet at 10 (dash-dot lines) and 50 (solid lines) $\mathrm{s}$ were compared with those for $1 \mathrm{~g}$ droplet (dashed lines for $10 \mathrm{~s}$ and doted lines for $50 \mathrm{~s}$ ) in Fig. 9 as well as in Fig. 10 with a normalised radius. The profiles of two droplets are similar at $10 \mathrm{~s}$. When the reaction time increases to $50 \mathrm{~s}$, lower carbon, higher oxygen, higher $P_{\mathrm{CO}}$, lower surface tension and lower critical bubble radius pro-

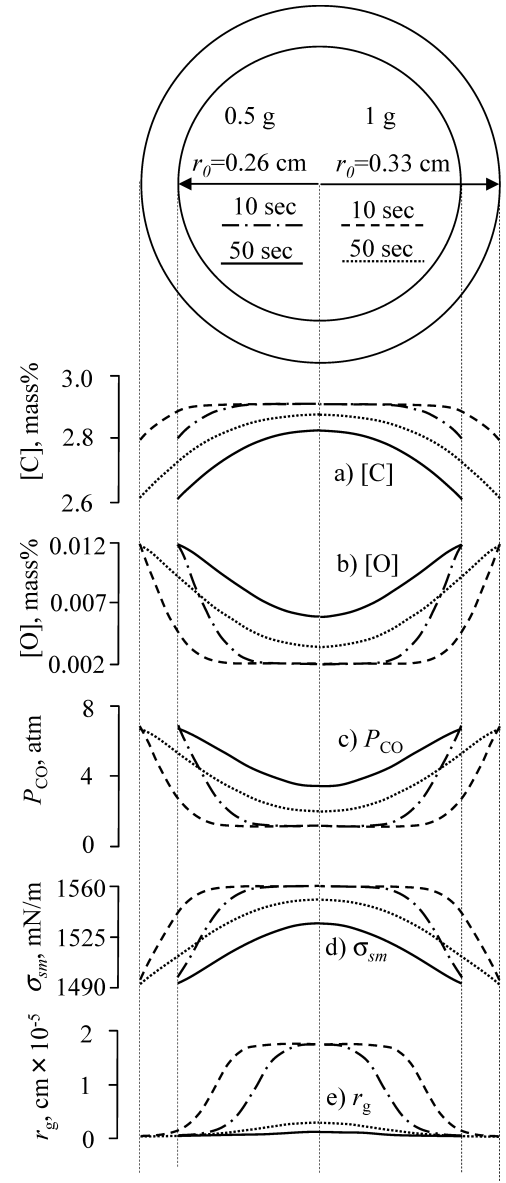

Fig. 9. Profiles of carbon concentration (a), oxygen concentration (b), CO pressure (c), surface tension (d) and critical bubble radius (e) at 10 and $50 \mathrm{~s}$ into reaction between a 0.5 or $1 \mathrm{~g}$ droplet ( 2.91 mass $\%$ carbon) and slag ( 5 mass $\%$ $\mathrm{FeO})$ at $1713 \mathrm{~K}$.

files were obtained for smaller droplet than those for larger droplet. This indicates the nucleation of $\mathrm{CO}$ bubble within the liquid would be easier for a smaller droplet. As mentioned previously in Sec. 4.3.1, the decarburisation rate dose not follow the expectation from proportionality between the rate and surface area. This is because the mass transfers occur throughout the droplet body which does not solely depend on the surface area. A contrast example was the observation by Sun and Pehlke ${ }^{35,36)}$ for a internal stirred droplet exposed to oxidizing gases, where the decarburisation was limited by the processes in the vicinity of the droplet surface, and the rate was found to be simply in proportion to the surface area of the droplet.

\section{Conclusions}

The reaction of a $\mathrm{Fe}-\mathrm{C}$ droplet with $\mathrm{FeO}$ bearing slag was analyzed with aid of a kinetic model that includes thermodynamic relations, diffusions in the slag and the droplet, and the interfacial reactions. The droplet swelling was interpreted by incorporating the kinetics of $\mathrm{CO}$ bubble nucleation within metal phase in the kinetic model. Decarburisation rate increases with increasing $(\mathrm{FeO}),[\mathrm{C}]$ and droplet size, and decreases with increasing [Si] and pressure. The decarburisation rate in unit surface area of the droplet also increases with increasing the droplet size. Initial slow de- 


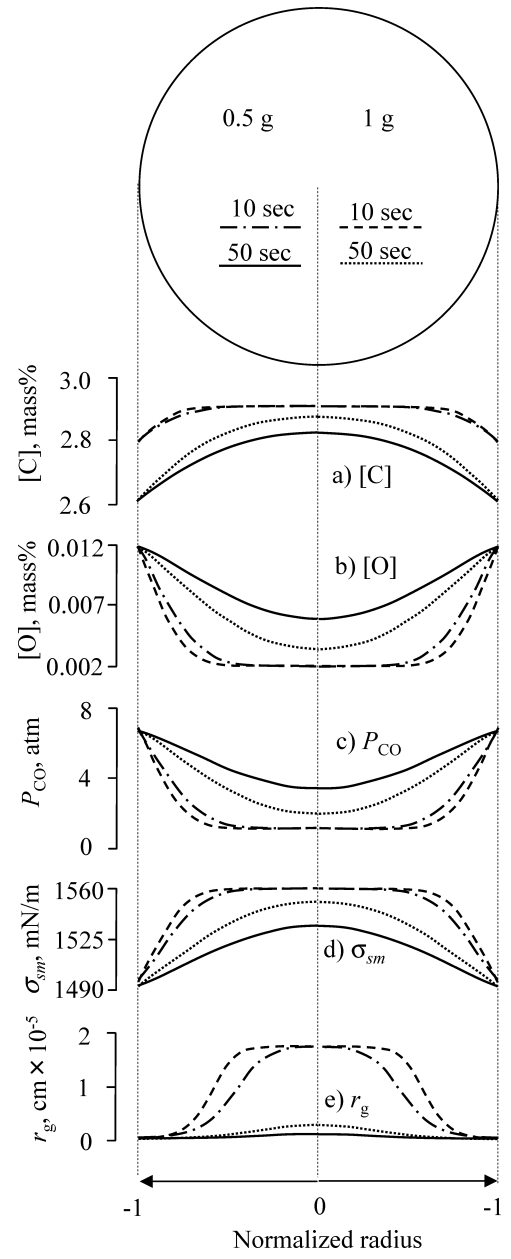

Fig. 10. Profiles of carbon concentration (a), oxygen concentration (b), CO pressure (c), surface tension (d) and critical bubble radius (e) at 10 and $50 \mathrm{~s}$ into reaction between a 0.5 or $1 \mathrm{~g}$ droplet $(2.91$ mass $\%$ carbon) and slag $(5 \mathrm{mass} \% \mathrm{FeO})$ at $1713 \mathrm{~K}$ using normalized radius of droplets.

carburisation occurs due to oxygen absorption and desiliconisation, and this stagnancy is more significant when contents of carbon and silicon in metal, ambient pressure and droplet size are increased or when $(\mathrm{FeO})$ is decreased. The swelling of the droplet occurs due to the CO bubble generation within the droplet. The conditions that promote swelling of the droplet during the reaction are higher carbon or lower silicon in the droplet, the smaller droplet size, lower ambient pressure and higher $\mathrm{FeO}$ in slag.

\section{Nomenclature}

$A:$ Surface area of the droplet $\left(\mathrm{cm}^{2}\right)$

$a_{i}$ : Activitis of carbon, oxygen or silicon, in metal or activities of $\mathrm{FeO}$ or $\mathrm{SiO}_{2}$ in slag

$D_{i}$ : Diffusivity of carbon, oxygen and silicon in molten iron $\left(\mathrm{cm}^{2} \mathrm{~s}^{-1}\right)$

$e_{j}^{i}$ : Interaction parameter between of carbon, oxygen, sulphur and silicon in metal

$f_{i}$ : Activity coefficient of carbon, oxygen and silicon in metal

$K_{i}:$ Equilibrium constant

$k_{\mathrm{s}}$ : Mass transfer coefficient in slag in gas $\left(\mathrm{cm} \mathrm{s}^{-1}\right)$

$k_{\mathrm{r}}$ : Decarburisation rate constant at surface $\left(\mathrm{mol} \mathrm{cm}{ }^{-2} \mathrm{~s}^{-1}\right.$ )
$M_{i}$ : Molecular weight of elements and oxide $\left(\mathrm{g} \mathrm{mol}^{-1}\right)$

[i]: Content of carbon, oxygen or silicon in metal (mass\%)

(i): Content of oxides in slag (mass\%)

$J_{i}$ : Materials fluxes in the radius direction of the droplet $\left(\mathrm{mol} \mathrm{s}^{-1}\right)$

$P_{\mathrm{CO}}: \quad$ CO pressure $(\mathrm{Pa})$

$P^{\circ}$ : Ambient pressure $(\mathrm{Pa})$

$r$ and $r_{\mathrm{o}}$ : Radius in droplet and that of the droplet $(\mathrm{cm})$

$r_{\mathrm{g}}$ : Critical nucleation radius of gas bubble in liquid (cm)

$r_{\mathrm{g}, \mathrm{av}}$ : Average critical nucleation radius of gas bubble in liquid $(\mathrm{cm})$

$T: \quad$ Temperature (K)

$t:$ Reaction time (s)

$X_{i}$ : Molar fraction of $\mathrm{FeO}$ or $\mathrm{SiO}_{2}$ in slag

$\gamma_{i}$ : Activity coefficient of $\mathrm{FeO}$ or $\mathrm{SiO}_{2}$ in slag

$\rho_{\mathrm{s}}$ : Density of slag $\left(\mathrm{g} \mathrm{cm}^{-3}\right)$

$\rho_{\mathrm{m}}$ : Density of metal $\left(\mathrm{g} \mathrm{cm}^{-3}\right)$

$\sigma:$ Interfacial tension $\left(\mathrm{mN} \mathrm{m}^{-1}\right)$

$\theta$ : Contact angle

Superscripts and subscripts

EQ : Equilibrium

s: Slag

m: Metal

g: Gas

$r_{0}$ : Quantity at interface

$r_{0}-d r$ : Quantity at a distance of $d r$ from the interface

\section{Acknowledgement}

The author wishes to thank Prof. D. Robertson of Missouri University for his discussions on this work.

\section{REFERENCES}

1) Z. Han and L. Holappa: ISIJ Int., 43 (2003), 1698.

2) G. A. Subagyo, K. S. Brooks and G. A. Irons: ISIJ Int., 43 (2003), 983.

3) S. Kobayashi: ISIJ Int., 33 (1993), 577.

4) K.-Y. Lee, H.-G Lee and P. C. Hayes: ISIJ Int., 38 (1998), 1248.

5) K.-Y. Lee, H.-G. Lee and P. C. Hayes: ISIJ Int., 38 (1998), 1242.

6) G. Brooks, Y. Pan, G. A. Subagyo and K. Coley: Proc. the Conference of Metallurgist, COM 2004, Hamilton, Ontario, Canada, (2004), 37.

7) D.-J. Min and R. J. Fruehan: Metall. Mater. Trans. B, 23B (1992), 29.

8) C. L. Molloseau and R. J. Fruehan: Metall. Mater. Trans. B, 33B (2002), 335.

9) H. Sun, K. Gao, V. Sahajwalla, K. Mori and R. D. Pehlke: ISIJ Int., 39 (1999), 1125

10) K. Gao, V. Sahajwalla, H. Sun, C. Wheatley and R. Dry: ISIJ Int., 40 (2000), 301.

11) A. Wu, P. C. Hayes and H.-G. Lee: ISIJ Int., 38 (1998), 213.

12) H. Sun, N. Yoneda, K. Nakashima and K. Mori: Tetsu-to-Hagané, 83 (1997), 1.

13) T. B. King: J. Soc. Glass Technol., 35 (1951), 241

14) I. Jimbo, A. Sharan and A. W. Cramb: Steelmaking Conf. Proc., ISSAIME, Warrendale, 76, (1993), 485.

15) E. Shibata, H. Sun and K. Mori: Metall. Mater. Trans. B, 30B (1999), 279.

16) W. Pan, M. Sano, M. Hirasawa and K. Mori: ISIJ Int., 31 (1991), 358.

17) H. Sun and K. Mori: ISIJ Int., 36 (1996), S34.

18) H. Sun, N. Kawai, N. Shinozaki and K. Mori: Technol. Rep. Kyushu Univ., 61 (1989), 441.

19) E. Shibata, H. Sun and K. Mori: Tetsu-to-Hagané, 85 (1999), 27. 
20) K. Mori, S. Hiwasa and Y. Kawai: J. Jpn. Inst. Met.. 44 (1980), 1282.

21) K. Mori, Y. Fukami and Y. Kawai: Trans. Iron Steel Inst. Jpn., 28 (1988), 315.

22) Y. Nakajima, M. Mukai, Y. Fukami, H. Sun, T. Moriya and S. Maruhashi: Tetsu-to-Hagané, 76 (1990), 1823.

23) E. Shibata, H. Sun and K. Mori: Tetsu-to-Hagané, 82 (1996), 575.

24) N. Shinozaki, M. Maeda and K. Mori: W. O. Philbrook Memorial Sym. Conf. Proc. ISS, Warrendale, PA, (1988), 91.

25) S. Doi, K. Mori and Y. Kawai: Tetsu-to- Hagané, 72 (1986), 1560.

26) The Japan Society for Promotion of Science, The 19 Committee on Steelmaking, "Recommended Values of Activity and Activity Coefficients, and Interaction Parameters of Elements in Iron Alloys," Steelmaking Data Sourcebook, Revised Edition, Gordon and Breach Science Publisher, Tokyo, Japan, (1988), 273.

27) H. R. Rein and J. Chipman: Trans. Metall. Soc. AIME, 233 (1964), 415 .
28) S. Ban-ya: ISIJ Int., 33 (1993), 2.

29) Y. Kawai, R. Nakao and K. Mori: Trans. Iron Steel Inst. Met., 24 (1984), 509

30) F. Heisterkamp and K. Lohberg: Arch. Eisenhüttenwes., 37 (1960), 813.

31) M. Kawakami, S. Yokoyama, K. Takagi, M. Nishimura and J. Kim: ISIJ Int., 37 (1997), 425.

32) R. E. Grace and G. Derge: Trans. Metall. Soc. AIME, 212 (1958), 331.

$33)$ C. Yamagata, Y. Kajiwara, S. Suyama and T. Miyake: ISIJ Int., 30 (1990), 740 .

34) T. Gore and G. S. F. Hazeldean: Ironmaking Steelmaking, 3 (1981), 167.

35) H. Sun and R. D. Pehlke: Metall. Mater. Trans. B, 26B (1995), 335.

36) H. Sun and R. D. Pehlke: Metall. Mater. Trans. B, 27B (1996), 854. 